\title{
The Profile of Public School Teachers' Research
}

\author{
Morfi Athina \\ Democritus University of Thrace, Alexandroupolis, Greece
}

\begin{abstract}
In the 21 st century, Greece, with the rapid social change and cultural-economic crisis of multi-ethnicity and information technologies, an up-to-date and systematic exploration of the role of teacher is necessary. This study investigated the academic and professional profile of primary and secondary public school teachers in Orestiada and presented this information in order to improve the quality and promote the education at the specific area.
\end{abstract}

Keywords: teacher, academic and professional profile, public school

\section{Introduction}

With the rapid technological development of the 21 st century and mass population movements, societies change become more and more multicultural. Correspondingly, today's education system, represented by its teachers, should be defined by interaction, mutual recognition, and cooperation between people of different social groups.

Tsardakis (1992) said, "The role of the teacher, like any social role, is configured and constituted within a particular historical society, which in turn just works there because it establishes and distributes social roles to its members and trains them." In fact, the education system today both upholds traditional pedagogy (teaching materialism), and encompasses modern pedagogy (Chatzidimou, 2010). The main educational objectives are guidance, reflection, and encouragement of student's independence and motivation (Taratori, 1999).

While according to Tagliante (1994), "The attitude of the teacher is correlated with his personality and, of course, with the methodology he applies." Undoubtedly, there are particular characteristics or behaviours that can improve a teacher's attitude and simultaneously improve their educational skill.

\section{The Research}

We undertook this research primarily out of personal interest in the topic, and mainly driven by the literature's strong indications on the importance of the teacher's role in primary and secondary education.

Primary and secondary school teachers usually have a decisive role in student management, guidance, and the creation of high standards in teaching. Their role is significant to kids and adolescents especially during teaching a foreign language. Nikolov and Djigunovic (2011) stated:

Teachers are fundamental in early childhood as they are not only the main sources of information and motivation, but are responsible for what happens in class.

Consequently, a thorough study that attempts to record the profile of primary and secondary school teachers ought to have a clear record of their details, features, studies, and general teaching experience, 
particularly their experience with managing classes of students.

The aim of the research is to analyse the components of the profile of the teachers that staff schools, from several aspects: (a) the professional; (b) the social; (c) the educational; (d) the psychological; (e) the academic; and (f) the cross-cultural, and to clarify how this study can contribute to the qualitative upgrade and the promotion of the education in the area.

The particular article is aimed at a research depiction of the academic and professional profile of the teacher.

The results of the current study are part of an extended study for the author's Ph.D. thesis.

Questionnaires were used as a main research tool-since they are popular for fieldwork despite their drawbacks (Altrichter, Posch, \& Somekh, 2001). We interviewed primary and secondary school teachers with a questionnaire of 40 questions, out of which specifically the first six referred to the participants' individual characteristics, nine questions referred to their academic qualifications, and six referred to their professional experience. We also conducted structured interviews from primary and secondary school teachers, in order to receive more information on the research topic.

\section{The Sample}

Primary and secondary school teachers of different ages and educational levels were selected to conduct this research. In total, 210 questionnaires were shared among primary and secondary schools in the town of Orestiada and 40 interviews were conducted for additional data.

For brevity, only the findings of the study related to the questionnaire's frequency and correlation analysis are presented in this article.

It is worth mentioning in advance that the questionaire analysis confirmed the findings of the interviews analysis, proving that, through "triangulation"-which is the application of the combination of two different research methodologies for the study of the research question, a confirmation of the findings was recorded, as it emerged from the application of both methodologies.

The use of both research methodologies and the results of their intersection increased significantly the validity and reliability of the research.

\section{Data Analysis}

\section{Frequencies}

The group of teachers who answered to the research's questionnaire consisted of both men and women. To determine the sample, $67.1 \%$ (141 teachers) of questionnaire participants were women and 32.9\% (69 teachers) were men. These teachers had various educational approaches, work experiences, and generally characteristics that confirmed the principle of sample differentiation.

Furthermore, participants present in the study analytically the whole a range of their acquired qualification. Particularly, 86 teachers (41\%) of the total sample hold a university degree; 51 teachers $(24.3 \%)$ are graduates from the Educational Training College; 44 teachers (21\%) have a degree from the Department of Primary School Education. Only 18 teachers $(8.6 \%)$ declare that they have done post-training; six teachers $(2.9 \%)$ hold a Ph.D., and five teachers (2.4\%) have a degree in technological education.

Years of work experience from the total sample of 210 were as follows:

(a) 53 teachers $(25.2 \%): 16$ to 20 years;

(b) 50 teachers $(23.8 \%)$ : over 21 years; 
(c) 45 teachers $(21.4 \%): 6$ to 10 years;

(d) 40 teachers (19\%): 11 to 15 years;

(e) 22 teachers $(10.5 \%)$ : under 5 years.

Two hundred teachers (95.2\%) answered that they were employed in the town of Orestiada, while six teachers $(2.9 \%)$ did not answer this question at all, and just four of them (1.9\%) mentioned the wider region of Evros.

Classes taught were as follows:

(a) 48 teachers $(22.9 \%)$ teach all year groups in high school;

(b) $32(15.2 \%)$ teach all grade groups in secondary school;

(c) $15(7.1 \%)$ teach all grade groups in primary school;

(d) $13(6.2 \%)$ teach Grade 1 of primary school;

(e) $18(8.6 \%)$ teach Grade 2 of primary school;

(f) $22(10.5 \%)$ teach Grade 3 of primary school;

(g) $28(1.3 \%)$ teach Grade 4 of primary school;

(h) $16(7.6 \%)$ teach Grade 5 of primary school;

(j) Seven (3.3\%) teach Grade 6 of primary school;

(k) Three (1.4\%) teach Class B of high school;

(l) Two (1\%) teach in Classes A, B, and C of secondary school;

(m) Two (1\%) teach Class $\mathrm{C}$ of high school.

\section{Data Analysis of the Academic Profile}

Fifty-seven point one percent (120 teachers) of the teachers that participated in the current research claimed to be very satisfied with their everyday class preparation. Twenty-eight point one percent (59 teachers) were highly satisfied with their everyday class preparation; 12.9\% (27 teachers) slightly satisfied; and $1.9 \%$ (four teachers) not satisfied at all.

Regarding the use of new technologies, $67.6 \%$ of teachers use new technology all the time. Thirty-seven teachers $(17.6 \%)$ often use technology. Thirty teachers $(14.3 \%)$ rarely use technology, and one teacher $(0.5 \%)$ does not use it at all.

The majority of teachers $(55.7 \%)$ frequently participate in seminars; $87(41.4 \%)$ rarely participate in seminars; and three (1.4\%) never or extremely rarely attend them.

Fourty-six point two percent (97 teachers) usually encourage students to take initiatives; $43.3 \%(91$ teachers) often do so; 6.2\% (13 educators) state that this never happens; and just 4.3\% rarely encourage children to take initiatives.

The most popular imposition of discipline is praise for 79 teachers $(37.6 \%)$ whereas 66 teachers $(31.4 \%)$ give examples to adapt discipline in class. Fifty-seven teachers $(27.1 \%)$ give advices; two teachers $(1 \%)$ give orders; whereas only one teacher $(0.5 \%)$ uses remuneration and ban of speech.

The majority of participants $(64.8 \%)$ believe that the most important teaching principle is "self-acting"; $27.1 \%$ (57 teachers) claim that it is the principle of supervision; 5.7\% (12 teachers) think it is the principle of individuality; and $2.4 \%$ (five teachers) think it is timeliness.

One hundred and fourty out of 210 teachers $(66.7 \%)$ state that their scientific training is very good; 37 of them $(17.6 \%)$ state that they are extremely well scientifically trained; 25 teachers $(11.9 \%)$ are a bit 
scientifically trained, and six teachers $(2.9 \%)$ are not scientifically trained at all. Two teachers $(1 \%)$ did not give any answer for this question.

Sixty-six point two percent (139 teachers) of the total sample claim to have sufficient pedagogical training; $22.4 \%$ (47 teachers) claim to be extremely well pedagogically trained; $7.1 \%$ (15 teachers) have a little pedagogical training; $2.9 \%$ (six teachers) have no pedagogical training at all, and $1.4 \%$ (three teachers) chose not to answer the question.

In the question regarding the natural gifts that make an educator more efficient in teaching, most of the teachers, $37.1 \%$ ( 78 teachers) answered the good heath condition/absence of disability. Twenty-seven point one percent (57 teachers) stated the vision, touch, and hearing abilities; $16.2 \%$ (34 teachers) think that this is the physical stamina and strength; $11 \%$ (23 teachers) answered the elocution; $7.6 \%$ (16 teachers) answered the individual characteristics; whereas just $1 \%$ (two teachers) answered the movement coordination.

For $52.4 \%$ (110 teachers), the teacher's most important spiritual gift is knowledge; for 17.1\% (36 teachers), it is communication and social skills; for $12.4 \%$ (26 teachers), it is organization; for $7.1 \%$ (15 teachers), it is adaptability; for $6.2 \%$ (13 teachers), it is the values and morals system; for 3.8\% (eight teachers), it is creativity; and for $0.5 \%$ (one teacher), it is the ability of enforcement-creativity and imagination respectively.

\section{Information Related to Professional Profile}

One hundred and ninety of the 210 participants (90.5\%) largely have faith in their personal skills in the performance of daily teaching and solving everyday problems in the classroom, and 17 teachers $(8.1 \%)$ say they have a high degree of faith in their personal skills. Only three teachers $(1.4 \%)$ indicate a small degree belief in their personal abilities.

Fifty-seven point six percent, namely 121 teachers, are highly satisfied in their choice of the profession, and $32.4 \%$ (68 teachers) are greatly satisfied. Only 9\%, 19 teachers, expresses low satisfaction, while 1\%, two teachers, has no satisfaction in their choice.

Due to their work, 106 teachers (50.5\%) say they feel a small degree of burnout or physical, emotional or psychological exhaustion; 55 teachers (26.2\%) say they feel burnout or exhaustion in large degree; 39 teachers $(18.6 \%)$ do not feel any exhaustion; six teachers $(2.9 \%)$ feel burnout very much; while four teachers $(1.9 \%)$ did not give any answer.

The motivation for the choice of the teaching profession for 144 teachers $(68.6 \%)$ was the love of children and teaching. Only 20 teachers $(9.5 \%)$ were motivated by the vocational rehabilitation, whereas 23 teachers (11\%) were motivated by their desire for education. A motivation for 12 teachers $(5.7 \%)$ was the educational model, while for eight teachers (3.8\%), the working conditions; for only two teachers $(1 \%)$, the working time; and for one teacher $(0.5 \%)$, the social prestige.

Interest is the most effective enhancement of educational adequacy for 57 teachers (27.1\%), patience for 53 teachers $(26.2 \%)$, flexibility for 50 teachers $(23.8 \%)$, imagination for 24 teachers $(11.4 \%)$, tolerance for 18 teachers $(8.6 \%)$, enthusiasm for six teachers $(2.9 \%)$, and humor for one teacher $(0.5 \%)$.

For 94 teachers (44.8\%), respect is the skill that brings better results in communication, while 50 teachers (23.8\%) report genuineness and authenticity as the most important feature for effective communication. For 19 teachers (9\%), the most important feature for effective communication is warmth and acceptance; for the $7.1 \%$ (15 teachers), it is empathy; and for $7.1 \%$ (15 teachers), it is the sharpness and clarity of speech. Only six teachers $(2.9 \%)$ consider facial expression as being the most important communication skill; for two teachers 
$(2 \%)$, it is the look and self-disclosure respectively. Finally, one teacher $(0.5 \%)$ considers posture as the most important feature.

\section{Results From the Correlations in the Questionnaire Responses}

Below we present the results obtained by the method of cross tables, which is the correlation between independent and dependent variables, and are referred to the academic and professional profile of the teacher.

The data analysis by this method showed the following results:

1. The skills to which teachers attribute great importance for effective communication with students in the classroom affect the degree of satisfaction they feel about the classroom's psychological atmosphere;

2. The more the teachers feel exhausted due to their work, the less they feel satisfied with their chosen profession;

3. The more teachers use new technologies, the less they believe they are scientifically trained in the subject they teach. This might sounds disruptive, but can be explained by the educational tenacity and professional willingness of teachers, which means that those teachers who know how to handle new technologies take it for granted and not as part of their scientific training;

4. Their incentive for profession selection was found to significantly affect their level of happiness and satisfaction. Depending on the incentive that encouraged teachers to choose this profession, they tend to feel more or less satisfied;

5. Depending on the ways they consider more important to strengthen the educational adequacy and those adopted by teachers their senses of self-knowledge are affected;

6. The degree of pedagogical training that teachers feel they have is influenced by the attitudes they consider important to strengthen the educational adequacy and also, influence them;

7. The more satisfaction teachers feel for the selection of the profession they follow, the less they seem to encourage students to take the initiative in conducting their courses;

8. The motivation for becoming a teacher affects the degree of satisfaction teachers feel in preparing lessons daily.

\section{Conclusions}

From the data analysis of the research, one can draw the following general conclusions:

1. Most teachers are well or very satisfied with the daily preparation of lessons, with a few exceptions that indicate the opposite.

2. New technologies seem to be part of the daily life of teachers as the majority of them use some or many new technologies. Almost half of the sample very often attends training courses for professional development both inside and outside the school unit, while the rest is rarely or never involved. Most of them have very good academic background, but less pedagogical training.

3. The most important physical requirements for effective teaching are a good state of health and the absence of a disability; the visual, touch, and hearing skills; physical strength and stamina; elocution and personal characteristics. While the most important mental gifts are knowledge, communication and social skills, organization, adaptability, values, morality system, and creativity.

4. It is important for both the teaching system and children that most teachers urge often or very often students to develop initiatives in conducting their courses. 
5. The main means of educating children is by example, followed by praise and advice, while the basic principle of teaching seems to be the principle of self-acting. Teachers consider that interest is the most effective enhancement of educational adequacy, while patience and flexibility are equally effective.

6. Special emphasis for effective communication between teachers and students in the classroom, is given mainly to the existence and development of specific communication skills on teacher's part, such as genuineness and authenticity, empathy, warmth and acceptance, as well as the sharpness and clarity of speech, while less importance is being given by research to the posture, self-disclosure, the look, and the clear loud tone of his voice.

7. Almost all teachers believe greatly in their teaching capabilities in the performance of daily teaching and everyday problems solving in the classroom, and feel greatly satisfied with their profession. Few teachers feel physically, emotionally, or psychologically exhausted because of working, and most say that when they do feel exhausted, it is to a small degree.

8. For most teachers, the basic motivation for choosing the teaching profession is the love for teaching and children, while the desire for education, vocational rehabilitation, educational model, working conditions, and the good working hours come next.

So, in summary, it could be argued that a public school teacher needs many important abilities and skills in order to really play a decisive role in the educational activities of their school, while coping with numerous and varied responsibilities - pedagogical, teaching, management, and social.

This shows the urgent need to strengthen the role of both the side of state and the educational institutions and science educators. Only by this way, and only after receiving the necessary assistance, teachers can meet the high demands of the students, the fellow teachers, and the expectations of their school in a continuously evolving society.

The continuous self-improvement and lifelong training of the teacher, always in conjunction with equal opportunities for the students and their constantly growing self-esteem, can lead to a the creation of a true, experiential learning groups buildt on the present and future of each learner, as a human being.

Societies are transformed, and change their foundations by sending messages to a dynamic two-way relationship. The quality of education espoused the quality and future of the whole society in every corner of the globe. Let the teacher become the body of knowledge and values, and the bridge that will firmly unite the school with the world and the child with life.

\section{References}

Altrichter, H., Posch, P., \& Somekh, B. (2001). Teachers investigate their work. Athens: Metaichmio Publications. Chatzidimou, D. (2010). Introduction to pedagogy. Thessaloniki : Afoi Kyriakidi Publishing.

Cohen, L., \& Manion, L. (1994). Reasearch methods in education. London: Routledge.

Nikolov, M., \& Djigunovic, J. M. (2011). All shades of every colour: An overview of early teaching and learning of foreign languages. Annual Review of Applied Linguistics, 31, 95-119.

Tagliante, C. (1994). The language class. Paris: CLE International.

Taratori, E. (1999). Interest in the educational process (Vol. 1, pp. 15-19). Alexandroupolis: Kinitro Publications.

Tsardaris, D. (1992). The social theory of roles. Athens: Skaraveos Publications. 